Mangoyi et al, Afr J Tradit Complement Altern Med. (2017) 14 (5): 156-165

https://doi.org/10.21010/ajtcam.v14i5.19

\title{
MECHANISMS OF ACTION OF TRADITIONAL HERBAL MEDICINES USED IN THE MANAGEMENT OF DIABETES MELLITUS: A REVIEW OF THE LITERATURE
}

\author{
Mangoyi Japhet $^{{ }^{*}}$, Ngcobo Mlungisi ${ }^{1}$, Gomo Exnevia ${ }^{1}$ \\ ${ }^{1}$ Traditional Medicine Laboratory, School of Nursing \& Public Health, University of KwaZulu-Natal, Howard \\ College, Durban 4001, South Africa
}

Corresponding Author E-mail: japhetmangoyi@gmail.com

\begin{tabular}{|c|}
\hline Article History \\
Received: 10, April. 2017 \\
Revised Received: 7, July. 2017 \\
Accepted: 10, July. 2017 \\
Published Online: 01, Oct. 2017 \\
\hline
\end{tabular}

\begin{abstract}
Background: The prevalence of diabetes mellitus is increasing rapidly in both developed and developing countries. There are various conventional medicines used for the management of the disease, but there is also increased interest in the use of traditional herbal medicines. Although the concepts of illness and diseases in traditional medicine may differ from conventional medicine the outcomes are similar. The antihyperglycemic effects of various herbal medicines prescribed by traditional healers in the management of diabetes mellitus have been proven scientifically using several in-vitro and in-vivo models as well as clinical studies in humans.

Materials and methods: Literature search was done in several databases. Firstly, the search was conducted using the key terms: diabetes mellitus and traditional medicine, diabetes mellitus and herbs, diabetes mellitus and plants, traditional concepts of health and sickness and diabetes mellitus. After identifying the herbs or plants used in diabetes a search was then conducted by name of herb and efficacy in management of diabetes mellitus.

Results: This review highlights the similarities and differences in mechanisms of action of various traditional herbal medicines and conventional medicines. The major observation is that, herbal medicines often have multiple mechanisms of action ideally making them combination therapies. The review further highlights the need to develop an algorithm of a minimum battery of in-vitro and animal studies that can provide solid evidence of the potential of traditional medicines as anti-diabetic treatments.

Conclusion: Traditional herbal medicines often have multiple phytoconstituents and hence multiple mechanisms of action ideally making them combination therapies.
\end{abstract}

Keywords: traditional herbal medicines, diabetes mellitus, mechanisms of action

\section{Introduction}

Normal glucose homeostasis is tightly controlled by three interconnected and interrelated processes: (1) glucose production in the liver through gluconeogenesis and glycogenolysis, (2) glucose uptake and utilization by peripheral tissues mainly skeletal muscle and adipose tissue, and (3) the action of insulin and counter regulatory hormones (including glucagon, somatostatin, growth hormone and corticosteroids) (Kumar et al., 2013). The metabolic effects of insulin can be summarized as anabolic, with increase in glycogenesis, decrease in gluconeogenesis and glycogenolysis, increase in protein synthesis and decrease in degradation of lipids.

Diabetes Mellitus (DM) is a metabolic disorder characterized by chronic hyperglycemia as a result of deficiency in insulin secretion, insulin action or often a combination of both. According to the International Diabetes Federation (IDF) in 2015, approximately 415 million people in the world live with DM, the majority of whom are between the age of $40-59$ years and 80\% live in low to middle income countries (International Diabetes Federation, 2015). The prevalence of DM is increasing rapidly in both developed and developing countries. This increase is more pronounced in countries undergoing a transition from traditional to modern lifestyles (International Diabetes Federation, 2015). IDF, in 2015 also reported that approximately 673 billion United States dollars, which is $12 \%$ of global health expenditure was spent on management of diabetes and its complications (International Diabetes Federation, 2015). 
There are two major types of diabetes mellitus. Type $1 \mathrm{DM}$ is characterized by an absolute deficiency of insulin secretion caused, most commonly, by autoimmune destruction of the pancreatic beta cells that produce the insulin (Kumar et al., 2013). Type 2 DM is usually caused by a combination of peripheral insulin resistance and an inadequate compensatory response of insulin secretion by the pancreatic beta cells (Kumar et al., 2013). Regardless of the type of DM, the clinical presentation and progression are the same. Similarly the complications of uncontrolled disease are the same, affecting the microvascular (kidneys, eyes and nerves) and macrovascular systems (Fowler, 2008).

Diabetes can be diagnosed by any of four criteria. The first criterion is glycated hemoglobin $\left(\mathrm{HbAl}_{\mathrm{c}}\right)$ level $\geq 6.5 \%$. This criterion is also considered the gold standard to assess adequacy of therapy and management of diabetes. The second criterion is a fasting blood glucose level $\geq 7 \mathrm{mmol} / \mathrm{L}$. Fasting is defined as no caloric intake for at least 8 hours. Fasting blood glucose level is the most commonly used in developing countries since $\mathrm{HbA} 1_{\mathrm{c}}$ testing may not be readily available. The third criterion is a 2 -hour blood glucose level $\geq 11.1 \mathrm{mmol}$ during a $75 \mathrm{~g}$ oral glucose tolerance test. The last criterion is a random blood glucose $\geq 11.1 \mathrm{mmol}$ with classic symptoms of hyperglycemia which are polyuria, polydipsia and polyphagia (Kumar et al., 2013).

The pathogenesis of the long term complications of DM are multifactorial but persistent hyperglycemia (glucotoxicity) seems to be the key factor (Kumar et al., 2013). Formation of advanced glycation end products which give rise to release of pro-inflammatory cytokines from macrophages, generation of reactive oxygen species in endothelial cells and increased pro-coagulant activity on endothelial cells is one mechanism that leads to development of both macrovascular and microvascular complications (Kumar et al., 2013). The reactive oxygen species are also implicated in worsening pancreatic beta cell dysfunction in diabetes mellitus (Kumar et al., 2013). Most of the diabetic complications are also related to the presence of glycated products in the blood and generation of free radicals (Kumar et al., 2013). Therefore, use of treatments that have antioxidant properties may delay or stop the development and progression of diabetes complications as well as promote regeneration of pancreatic beta cells.

Management of DM using conventional drugs is achieved through supplementation of insulin, increasing insulin secretion from the pancreas, increasing insulin sensitivity in peripheral tissues especially skeletal muscle, decreasing the rate of glucose absorption in the gut and increasing glucose excretion via the kidney. The drugs can be classified as insulins, insulin secretagogues (sulfonylureas, meglitinides, glucagon like peptide agonists, dipeptidylpeptidase IV inhibitors), insulin sensitizers (metformin, thiazolidinediones), alpha glucosidase inhibitors (acarbose and miglitol) and selective sodium-glucose transporter 2 inhibitors (Inzucchi et al., 2012; Nair \& Wilding, 2010).

Despite the availability of the various classes of these conventional medicines the morbidity and mortality due to DM continues to increase globally (International Diabetes Federation, 2015). This is partly because none of the medicines results in cure of the disease. With disease progression, Type 2 DM patients move from single oral drug regimens to oral combination therapy and eventually to combination therapy that includes insulin injections (Inzucchi et al., 2012). The use of the conventional drugs is also often associated with adverse side effects such as severe hypoglycemia (insulin, sulfonylureas), lactic acidosis and vitamin $\mathrm{B}_{12}$ deficiency (biguanides), peripheral edema, bone weakening and hence fractures (thiazolidinediones) and abdominal discomfort (alpha-glucosidase inhibitors) (Lorenzati et al., 2010). Further, the cost of these conventional medicines is beyond the reach of many people who live in low resource settings such as Africa (International Diabetes Federation, 2015). Therefore, the search for more effective, cheaper and safer alternative treatments remains essential.

Herbal medicines are commonly used in traditional medicine (TM) practice for the management of noncommunicable diseases including DM (Z. Wang et al., 2013; World Health Organisation, 2012). People use herbal medicines for various reasons. Herbal medicines are perceived to have higher effectiveness, less side effects since they are of natural origin, relatively low cost and more accessible in remote areas (World Health Organisation, 2012). Therefore, research in these perceived benefits has become even more important to promote rational use, improve the action and stability of the herbal medicines by improving the formulations, and identify new chemical entities for management of DM.

Phytochemical screening and isolation has identified various phytoconstituents with antidiabetic effects. Among the phytoconstituents, the main actives are alkaloids, amino acids, glycosides, guanidine, steroids, polysaccharides, proteins, terpenoids, inorganic ions and peptidoglycans. This review article highlights the potential mechanisms of action of various traditional herbal medicines that were shown to be efficacious in various models of diabetes. The review discusses the similarities and differences between the mechanisms of action of the herbal medicines and conventional medicines used in the management of diabetes mellitus. The review also highlights the potential role of herbal medicines in the prevention and/or treatment of diabetes complications. The review then concludes with suggestions of some key parameters that can be used to validate effectiveness of traditional medicines and argues that society may benefit more if science not only emphasized isolation of active chemical entities and drug development, but focuses on improving the action of the traditional herbal medicines in the forms used by traditional healers. This will have far greater efficiency in research as well as impact on morbidity and mortality due to diabetes mellitus.

\section{Concepts of Health and Sickness in Traditional Medicine and Diabetes Mellitus}

The conventional medicine approach is founded on empirical evidence, which has led to the isolation of observable and tangible etiological factors in the understanding and treatment of illness. A similar approach has been 
adopted in developing the therapeutic procedures to combat the causes of illness. This approach largely revolves around finding active compounds specific for the desired effect. In the traditional healing context, health is viewed not as an isolated phenomenon but is encompassing and includes other factors that may not be considered in conventional medicine. Good health is therefore defined by means of a harmonious working and co-ordination of this integrated view (Busia, 2005; Okpako, 1999). Therefore it is within this world-view and metaphysics that appropriate and accurate African concepts of health, diseases and treatment can be derived and understood (Dlamini, 2006; Omonzejele, 2008). As the traditional concepts of health and illness are encompassing, the approach to management and treatment of illness is holistic (Omonzejele, 2008). Theoretical assumptions that traditional healers make about the origin of illness are consistent with the methods of treatment of the illness. While medical scientists may regard this approach as unscientific, users and practitioners of TM appreciate its rationality in the context it operates (Okpako, 1999).

Similarly, there are a number of differences between conventional and traditional medicine approaches to the management of diabetes mellitus. Conventional medicines used in DM target specific receptors for them to bring about therapeutic value, and normally one chemical entity has one mechanism of action. Unlike conventional medicines, traditional herbal medicines may contain various active ingredients targeting multiple mechanisms of action, ideally making the traditional herbal medicines combination therapies. In TM practice, the focus is not only on the blood glucose but about the wellness of the human being, hence the multiple phytoconstituents and multiple herbs normally incorporated in traditional herbal mixtures (Baldé et al., 2006; Peltzer et al., 2001; Tong et al., 2012). Whilst the conventional medicine approach defines DM as incurable, in African traditional medicine DM is a temporary condition that can be cured with the help of the ancestors (Awah, 2006).

\section{Efficacy of traditional herbal medicines used to treat diabetes mellitus}

The use of TM in the management of DM dates back to many centuries ago especially in Chinese and Indian TM practice. As later discussed, several herbal medicines have been shown to reduce blood glucose levels or reduce progression of diabetes complications. Some of the traditional medicines that have been extensively studied and have shown definitive efficacy as antidiabetic agents are discussed below.

Accumulating pieces of evidence demonstrate that leaves of Gymnema syvestre have antidiabetic properties. In 1990, Shanmugasundaram et al evaluated the effectiveness of G. sylvestre in 27 Type 1 DM patients in combination with insulin therapy (Shanmugasundaram et al., 1990). The extracts at the dose of 400mg daily for 18 months in combination with insulin therapy, significantly decreased fasting blood glucose, $\mathrm{HbA}_{1 \mathrm{C}}$ and serum lipids of the patients compared to a similar group who received insulin only (Shanmugasundaram et al., 1990). In another study, 200mg of ethanolic extract of G. sylvestre significantly reduced fasting blood glucose level and $\mathrm{HbA}_{1 \mathrm{C}}$ in diabetic patients (Nahas \& Moher, 2009). In an open-label clinical trial with 58 Type 2 diabetic patients, 500mg G. sylvestre leaf extracts taken daily for 3 months (Kumar et al., 2010) induced a significant reduction in polyphagia, blood glucose and $\mathrm{HbA}_{1 \mathrm{C}}$ compared to the control group. Administration of G. sylvestre to Type $2 \mathrm{DM}$ patients at a dose of $1 \mathrm{~g}$ /day for 2 months, also led to significant decreases in fasting blood glucose and early post-prandial blood glucose levels accompanied by increases in insulin and C-peptide in the blood (Al-Romaiyan et al., 2010). In the same study, extracts of G. sylvestre stimulated insulin secretion from isolated human islets of Langerhans (Al-Romaiyan et al., 2010).

Trigonella foenum-graecum seed was used in ancient Egypt as a remedy for DM and spread to Asian countries such as China and India (Bawadi et al., 2009). T. foenum-graeceum was reported to have hypoglycemic effects in rats as early as 1974 (Mishkinsky et al., 1974). In a study in diabetic patients, insulin levels were significantly higher in the $T$. foenum-graecum treatment group compared to the placebo treatment group (Mathern et al., 2009). Sharma et al, 1990, showed that the defatted seeds of T. foenum-graecum administered to Type $1 \mathrm{DM}$ patients at a dose of $100 \mathrm{~g}$ daily for 10 days significantly lowered fasting blood glucose, total cholesterol, low-density lipoproteins and tryglycerides (Sharma et al., 1990). A meta-analysis on the effect of herbal supplement in Type 2 DM patients showed that T. foenum-graecum reduced $\mathrm{HbA}_{1 \mathrm{C}}$ by $1.13 \%(\mathrm{P}=0.03$ ) (Suksomboon et al., 2011). In a double blind placebo controlled study, T. foenumgraecum was shown to improve glycemic control and insulin resistance in mild Type 2 diabetic patients (Gupta et al., 2001).

Momordica charantia is one of the most extensively studied herbal medicines that is used in the management of DM. The extracts of $M$. charantia reduced blood glucose levels and improved glucose tolerance comparable to conventional medicines in diabetic rat models (Ahmed et al., 2004; Ahmed et al., 2001; Sarkar et al., 1996; Virdi et al., 2003; Welihinda et al., 1986). The efficacy of M. charantia in humans has also been documented (Welihinda et al., 1986). Malik et al. 2009, compared the effects of M. charantia to rosiglitazone (thiazolidinedione which has since been banned because of cardiovascular side effects) in 25 Type 2 DM patients (Malik et al., 2009). Administration of 55ml/day of $M$. charantia juice for 5 months resulted in better control of diabetes and its related complications especially diabetes retinopathy and myocardial infarction compared to rosiglitazone (Malik et al., 2009). Ahmad et al. (1999) reported that drinking an aqueous suspension of the vegetable pulp of $M$. charantia resulted in a significant reduction in fasting blood glucose and post-prandial blood glucose levels in 86 out of 100 patients with Type 2 DM (Ahmad et al., 1999).

One of the most successful stories of TM research in DM was the discovery of metformin, a biguanide which is currently the backbone of Type 2 DM treatment. Metformin was developed based on the findings that guanidine like 
compounds isolated from Galega officinalis significantly reduced blood glucose levels (Bailey \& Day, 2004). Guanidine compounds however, were too toxic for clinical use (Muller \& Rheinwein, 1927). Through a series of testing and research, biguanides were then developed and shown to retain the antidiabetic effects of the guanidine like compounds yet safer to use clinically (Hesse \& Taubmann, 1929; Mehnert \& Seitz, 1958; Slotta \& Tsesche, 1929; Sterne, 1957; Ungar et al., 1957).

The success of metformin discovery has not been emulated with any other herbal medicine. This is possibly because other herbal medicines do not have one single chemical entity that is as highly active in the management of DM. Rather, a synergistic combination of effects and mechanisms by various phytoconstituents is responsible for the blood glucose lowering properties. This can be a lesson to the scientific community to not only look to the road of drug discovery but to try and improve the action of these herbal medicines as close to their traditional use as possible. Investing into research on the formulations of these raw herbal medicines may help in improving their stability and safety, which may reduce the marginalization of traditional herbal medicine use in DM.

\section{Mechanisms of action of traditional herbal medicines in DM management Antioxidant properties}

Free radicals may be responsible for development and progression of DM as well as development and progression of DM complications (Baynes \& Thorpe, 1999). The free radicals that are most implicated in DM and its complications are the superoxides, hydroxyl and lipid peroxides (Oberley, 1988). Therefore, antioxidants could potentially slow down, prevent and treat some of the complications. A number of herbal medicines have been proven to have antioxidant properties. These properties are suggested to be partly responsible for the antidiabetic effects.

In one study, extracts of Emblica officinalis, Terminalia belerica, Terminalia chebula and a combination of all the 3 extracts were shown to scavenge free radicals in-vitro (Sabu \& Kuttan, 2002). Green tea polyphenols (GTP) from Camellia sinensis were shown to have free radical scavenging properties both in vitro and in vivo studies (Sabu et al., 2002). Administration of GTP for 18 days resulted in significantly lower blood glucose levels in alloxan induced diabetic rats. Administration of GTP $(100 \mathrm{mg} / \mathrm{kg})$ was also shown to considerably reverse alloxan-induced pancreatic cell damage (Sabu et al., 2002). T. foenum-graecum extracts reduced oxidative stress, lowered lipid peroxidation and significantly increased antioxidant systems in animal models of DM (Annida et al., 2005).

Berberine, an isoquinoline alkaloid from Coptis sinensis was shown to reverse renal dysfunction in rats with diabetic nephropathy by decreasing blood glucose levels, reduction of the oxidative stress and suppressing the polyol pathway (sorbitol-aldose reduction) which is implicated in development of diabetic complications (Liu et al., 2008). Rhus hirta fruit extracts, Solidago Canadensis root extracts, Amarantus hypochondriacus seed extracts have higher free radical scavenging properties than ascorbic acid hence maybe utilized in preventing, reducing or stopping the progression of pancreatic beta cell destruction caused by free radicals as well as halting the progression of diabetes complications (McCune \& Johns, 2002; Nsimba et al., 2008). The antioxidant properties of M. charantia have also been associated with the antidiabetic activity of the plant extracts (Kubola \& Siriamornpun, 2008; Park et al., 2007; Sen et al., 2014).

The anti-oxidant properties of traditional herbal medicines make them potential supplements to conventional medicines to reduce and/or reverse pancreatic beta cell damage and hence development and progression of the complications of DM.

\section{Increase in insulin secretion}

In advanced type $2 \mathrm{DM}$ there is reduced insulin secretion making insulin secretagogues logical options for management of the disease. Some herbal extracts were shown to increase insulin secretion though the mechanisms have not been clearly elucidated. G. syvestre leaf extracts were shown to stimulate insulin secretion in-vitro by increasing membrane permeability of pancreatic beta cells resulting in influx of calcium which then leads to insulin secretion (Persaud et al., 1999). Slow acting protein extract from fruit pulp of M. charantia increased insulin secretion in Streptozotocin-induced diabetic rats as evidenced by increased plasma insulin concentrations in treated compared to control animals (Yibchok-anun et al., 2006). The increase was attributed to activation of glucokinase hence lowering the glucose threshold for insulin secretion in the pancreas (Rathi et al., 2002). Similarly, T. foenum-graecum extracts increased insulin secretion in animal studies; the increase being attributed to 4-hydroxyleucine, an amino acid mimicking the insulin secreting properties of the gluconeogenic amino acids arginine and leucine (Broca et al., 2000).

\section{Regeneration of the pancreatic beta cells}

Destruction of the pancreatic beta cells is responsible for the onset of Type $1 \mathrm{DM}$ and may also occur in late stage Type 2 DM especially when the patients are taking insulin secretagogues particularly the sulfonylureas (Del Guerra et al., 2005; Maedler et al., 2005). Currently, there is no conventional medicine that works by promoting the regeneration of pancreatic beta cells. A formulation that has such properties would be novel and potentially could cure both type 1 and type 2 DM. 
Leaf extracts of $G$. sylvestre were shown to promote pancreatic beta cell regeneration in alloxan-induced diabetic Wistar rats (AHMED et al., 2010). Extracts of $G$. syvestre increased both the pancreas mass and the liver glycogen content levels (AHMED et al., 2010). Berberine, from Coptis sinensis restored damaged pancreatic tissues in alloxan induced diabetic rats (Liu et al., 2008; Zhou et al., 2009). Pancreatic beta cell regeneration was also demonstrated with Momordica charantia (Hafizur et al., 2011; Singh \& Gupta, 2007b), Cantaranthus roseus (Ahmed et al., 2010), Nigella sativa (Abdelmeguid et al., 2010; Kanter et al., 2009), Allium sativum (Albajali et al., 2011) and Syzygium cumini (Singh \& Gupta, 2007a). These findings suggest that these extracts can potentially cure Type $1 \mathrm{DM}$ as well as play an important role in management of Type $2 \mathrm{DM}$.

\section{Increase in insulin sensitivity and glucose uptake}

One of the most prominent features of Type $2 \mathrm{DM}$ is insulin resistance often times as a result of obesity (Boden \& Shulman, 2002; Inzucchi et al., 2012). Several studies assessing the effects of traditional herbal medicines on insulin sensitivity and glucose uptake have been conducted. A protein from fresh fruit pulp of $M$. charantia increased the uptake of 2-deoxyglucose in $\mathrm{C} 2 \mathrm{C} 12$ cells (from the myocyte) in-vitro by $28 \%$ comparable to $37 \%$ increase in uptake induced by insulin (Yibchok-anun et al., 2006). This could be due to a direct effect of the extract on GLUT-4 transporters in the muscle cells or promotion of the translocation of these transporters resulting in the increase in glucose uptake. In the same study, M. charantia protein extract and insulin also increased 2-deoxyglucose uptake in 3T3-L1 adipocytes by 2.4 fold and 6.3 fold respectively, compared to the basal control group (Yibchok-anun et al., 2006). The ethyl acetate extract from $M$. charantia was also shown to activate both PPAR $\gamma$ and $\alpha$ receptors leading to the modulation of insulin receptors. This could explain the increase in insulin sensitivity and glucose utilization in muscle cells and adipocytes (Chao \& Huang, 2003; Chuang et al., 2006).

The effect of Coptis sinensis extracts on glucose homeostasis has been attributed to berberine, commonly present in the plant rhizomes, bark, roots and stems of the plant. Administration of berberine (200mg daily), via oral gavage in diabetic rats decreased fasting blood glucose levels, triglycerides, low density lipoproteins and total cholesterol and increased high density lipoprotein levels (Yu et al., 2005). Berberine increases GLUT 4 translocation in both myotubes and adipocytes (Kaleem et al., 2006), increases the expression of PPAR $\gamma$ and $\alpha$ proteins in the liver (Zhou \& Zhou, 2010; Zhou et al., 2008), increases the expression of insulin receptors in both the skeletal muscles and liver; and increases glucose uptake by glucose utilizing tissues in the presence of insulin (Kong et al., 2009).

\section{Alpha glucosidase and alpha amylase inhibition}

Alpha amylases and alpha glucosidases are responsible for breakdown of complex polysaccharides to oligosaccharides, disaccharides, and glucose. Inhibition of these enzymes decreases the rate of glucose absorption resulting in a decrease in post prandial blood glucose levels. Several herbal medicines have been shown to inhibit alpha glucosidase and amylase enzymes. The plants include, guava leaves (Wang et al., 2010), Adhatoda vasica (Gao et al., 2008), Baccharis trimera (Oliveira et al., 2005), Bergenia ciliate (Bhandari et al., 2008), Brachylaena discolor (Mellem et al., 2015), G. sylvestre (Luo et al., 2001), M. charantia (Uebanso et al., 2007), Phyllantus amarus (Ali et al., 2006), Pinus densiflora (Kim et al., 2005; Schäfer \& Högger, 2007), and Tourbefortia hartwegiana (Ortiz-Andrade et al., 2007).

\section{Dipeptidyl peptidase IV (DPP-IV) inhibition}

The DPP-IV enzyme is responsible for the breakdown of incretin hormones (GLP-1 and Glucose-dependent insulinotropin polypetide). Incretin hormones increase insulin synthesis and release from pancreatic beta cells and reduce glucagon secretion from pancreatic alpha cells. Therefore, the inhibition of DPP-IV results in increased insulin synthesis and release and reduce glucagon secretion. Protein hydrolyzates from Amarantus hypochondriacus reduced postprandial glycemia in streptozotocin-induced diabetic mice, possibly through inhibition of DPP-IV as observed in an in-vitro study (Soriano-Santos et al., 2015).

\section{Sodium-glucose transporter - 1 (SGLT-1) inhibition}

SGLT-1 is a transporter that is found in the brush border of the small intestines which is responsible for absorption of glucose. Therefore, inhibition of SGLT-1, just like alpha glucosidase inhibitors, results in decreased absorption of glucose in the small intestines. The models to study inhibition of SGLT-1 include brush border membrane vesicles (BBMV) prepared from apical membrane and vesicles prepared from basolateral membrane (BLMV) of the small intestines (Soumyanath, 2005). Extracts of G. sylvestre were shown to inhibit intestinal SGLT-1 and hence reduce absorption of glucose from the small intestines (Y. Wang et al., 2014). Extracts of T. foenun-graecum, Camellia sinensis and Green Tea Polyphenols inhibited glucose absorption in BBMV models (Al-Habori et al., 2001)' (Kobayashi et al., 2000). Since there is no SGLT-1 inhibitor among the conventional anti-diabetic medicines, this is an important area of future research.

A comparison of the mechanisms of action of conventional and some herbal medicines is summarized in the table below. 
Table: Comparison of mechanisms of action of conventional medicines with TM

\begin{tabular}{|c|c|c|c|c|c|c|c|}
\hline & $\begin{array}{l}\text { Decreased rate } \\
\text { of } \\
\text { carbohydrate } \\
\text { absorption }\end{array}$ & $\begin{array}{l}\text { Stimulation of } \\
\text { insulin } \\
\text { secretion }\end{array}$ & $\begin{array}{l}\text { Activation of } \\
\text { PPAR }\end{array}$ & $\begin{array}{l}\text { Increase in } \\
\text { insulin } \\
\text { receptor } \\
\text { sensitivity }\end{array}$ & $\begin{array}{l}\text { Regeneration } \\
\text { or decrease in } \\
\text { apoptosis of } \\
\text { B-cells }\end{array}$ & $\begin{array}{l}\text { Antioxidant } \\
\text { activity }\end{array}$ & $\begin{array}{l}\text { Increase in } \\
\text { glucose } \\
\text { excretion }\end{array}$ \\
\hline \multicolumn{8}{|l|}{ Conventional Medicines } \\
\hline Alpha glucosidase inhibitors & $*$ & & & & & & \\
\hline Amylinomimetics & $*$ & $*$ & & & & & \\
\hline Biguanides & & & & $*$ & & & \\
\hline DPP-IV inhibitors & & $*$ & & & & & \\
\hline GLP-1 agonists & & $*$ & & & & & \\
\hline Meglitinides & & $*$ & & & & & \\
\hline SGLT-2 inhibitors & & & & & & & $*$ \\
\hline Sulfonylureas & & $*$ & & & & & \\
\hline Thiazolidinediones & & & $*$ & & & & \\
\hline \multicolumn{8}{|l|}{ Herbal medicines } \\
\hline Adhatoda vasica & $*$ & & & & & & \\
\hline Allium sativum & & & & & $*$ & $*$ & \\
\hline Brachylaena discolor & $*$ & & & & & & \\
\hline Camelia sinensis & $*$ & & & & & $*$ & $*$ \\
\hline Catharanthus roseus & & & & & $*$ & $*$ & \\
\hline Coptis sinensis & & & $*$ & $*$ & $*$ & $*$ & \\
\hline G.sylvestre & $*$ & $*$ & & $*$ & $*$ & $*$ & \\
\hline M. charantia & $*$ & $*$ & $*$ & $*$ & $*$ & $*$ & \\
\hline Nigella sativa & & & & & $*$ & $*$ & \\
\hline Panax ginseng & & & & $*$ & & $*$ & \\
\hline Phyllantus amarus & $*$ & & & & & & \\
\hline Rhus hirta & & & & & & $*$ & \\
\hline Solidago Canadensis & & & & & & $*$ & \\
\hline Syzygium cumini & & & & & $*$ & $*$ & \\
\hline T. foenum-graecum & $*$ & $*$ & & & $*$ & $*$ & \\
\hline Tourbefortia hartwegiana & $*$ & & & & & & \\
\hline
\end{tabular}




\section{Conclusion}

Clearly, herbal medicines have multiple mechanisms possibly because of the multiple phytoconstituents, which effectively make them combination therapies. In addition, the multiple phytoconstituents may make traditional herbal medicines effective for the whole metabolic syndrome compared to conventional medicines that mainly focus on diabetes with limited or no effect on the other pathophysiological pathways of the metabolic syndrome.

The review has discussed several in-vitro and in-vivo models that have been used to evaluate efficacy and study possible mechanisms of action of herbal medicines used to treat diabetes. Clearly, there is need for consensus on the minimum evidence that is required to conclude that a particular traditional medicine is truly anti-diabetic, and build the necessary evidence towards human studies. This means that a minimum algorithm of in-vitro and in-vivo models to assess the anti-diabetic effects of herbal medicines is therefore required.

Amongst the in-vitro models, alpha glucosidase inhibition and antioxidant activity have been extensively used in evaluating anti-diabetic potential of traditional herbal medicines. Models that assess the other potential mechanisms of action need to be developed, optimized and utilized in diabetes research. Research should also focus on improving the action of traditional herbal medicines in the forms used by the traditional healers as much as it focuses on isolation of active chemical entities.

\section{Acknowledgements}

The financial assistance of the National Research Foundation (NRF) towards this research is hereby acknowledged. Opinions expressed and conclusions arrived at, are those of the author and not necessarily to be attributed to the NRF.

Competing Interest: Authors declare that there are no competing interests.

\section{References}

1. Abdelmeguid, NE., Fakhoury, R, Kamal, SM, \& Al Wafai, RJ. (2010). Effects of Nigella sativa and thymoquinone on biochemical and subcellular changes in pancreatic $\beta$-cells of streptozotocin-induced diabetic rats. J Diabetes, 2(4), 256-266.

2. Ahmad, N., Hassan, MR, Halder, H, \& Bennoor, KS. (1999). Effect of Momordica charantia (Karolla) extracts on fasting and postprandial serum glucose levels in NIDDM patients. Ban Med Res Cou Bull, 25(1), 11-13.

3. AHMED, A., BAKRUDEEN, A, RAO, AS, \& RAO, MV. (2010). In vitro callus and in vivo leaf extract of Gymnema sylvestre stimulate $\beta$-cells regeneration and anti-diabetic activity in Wistar rats. Phytomed, 17(13), 1033-1039.

4. Ahmed, I., Adeghate, E, Cummings, E, Sharma, AK, \& Singh, J. (2004). Beneficial effects and mechanism of action of Momordica charantia juice in the treatment of streptozotocin-induced diabetes mellitus in rat. Mol \& Cel Bio, 261(1-2), 63-70.

5. Ahmed, I., Lakhani, MS, Gillett, M, John, A, \& Raza, H. (2001). Hypotriglyceridemic and hypocholesterolemic effects of anti-diabetic Momordica charantia (karela) fruit extract in streptozotocin-induced diabetic rats. Diabetes Res \& Clin Prac, 51(3), 155-161.

6. Ahmed, MF., Kazim, SM, Ghori, SS, Mehjabeen, SS, Ahmed, SR, Ali, SM, \& Ibrahim, M. (2010). Antidiabetic activity of Vinca rosea extracts in alloxan-induced diabetic rats. Int J Endocrinol, 2010.

7. Al-Habori, M., Raman, A, Lawrence, MJ, \& Skett, P. (2001). In vitro effect of fenugreek extracts on intestinal sodiumdependent glucose uptake and hepatic glycogen phosphorylase A. J Diabetes Res, 2(2), 91-99.

8. Al-Romaiyan, A., Liu, B., Asare-Anane, H., Maity, CR., Chatterjee, SK, Koley, N, Amiel, SA., Biswas, T, Chatterji, A, Huang, GC, Persaud, S.J, Jones, PM, (2010). A novel Gymnema sylvestre extract stimulates insulin secretion from human islets in vivo and in vitro. Phytother Res, 24(9), 1370-1376.

9. Albajali, AA., Nagi, AH, Shahzad, M, Ullah, MI, \& Hussain, S. (2011). Effect of Allium sativa L. on pancreatic. cells in comparison to Nigella sativa L. in streptozotocin induced diabetic rats. J Med Plants Res, 5(24), 5779-5784.

10. Ali, H., Houghton, PJ, \& Soumyanath, A. (2006). $\alpha$-Amylase inhibitory activity of some Malaysian plants used to treat diabetes; with particular reference to Phyllanthus amarus. J Ethnopharmacol, 107(3), 449-455.

11. Annida, B., Prince, P, \& Mainzen, S. (2005). Supplementation of fenugreek leaves reduces oxidative stress in streptozotocin-induced diabetic rats. J Med Food, 8(3), 382-385.

12. Awah, P. (2006). Diabetes and traditional medicine in Africa. Diabetes Voi, 51(3), 24-26.

13. Bailey, CJ., \& Day, C. (2004). Metformin: its botanical background. Prac Diabetes, 21(3).

14. Baldé, NM, Youla, A, Baldé, MD, Kaké, A, Diallo, MM, Baldé, MA, \& Maugendre, D. (2006). Herbal medicine and treatment of diabetes in Africa: an example from Guinea. Dia \& Met, 32(2), 171-175.

15. Bawadi, HA., Maghaydah, SN, Tayyem, RF, \& Tayyem, RF. (2009). The postprandial hypoglycemic activity of fenugreek seed and seeds' extract in type 2 diabetics: A pilot study. Pharmacog Mag, 5(18), 134. 
16. Baynes, JW., \& Thorpe, SR. (1999). Role of oxidative stress in diabetic complications: a new perspective on an old paradigm. Diabetes, 48(1), 1-9.

17. Bhandari, MR., Jong-Anurakkun, N, Hong, G, \& Kawabata, J. (2008). $\alpha$-Glucosidase and $\alpha$-amylase inhibitory activities of Nepalese medicinal herb Pakhanbhed (Bergenia ciliata, Haw.). Food Chem, 106(1), 247-252.

18. Boden, G., \& Shulman, GI. (2002). Free fatty acids in obesity and type 2 diabetes: defining their role in the development of insulin resistance and $\beta$-cell dysfunction. Eur J Clin Inves, 32(s3), 14-23.

19. Broca, C., Manteghetti, M., Gross, R., Baissac, Y., Jacob, M., Petit, P., Sauvaire, Y., Ribes, G. (2000). 4Hydroxyisoleucine: effects of synthetic and natural analogues on insulin secretion. Eur J Pharmacol, 390(3), $339-345$.

20. Busia, Kofi. (2005). Medical provision in Africa-Past and present. Phytother Res, 19(11), 919-923.

21. Chao, CY., \& Huang, C. (2003). Bitter Gourd (Momordica charantia) Extract Activates Peroxisome Proliferator-Activated Receptors and Upregulates the Expression of the Acyl CoA Oxidase Gene in H4IIEC3 Hepatoma Cells. J Biomed Sci, 10(6), 782-791.

22. Chuang, C., Hsu, C, Chao, C, Wein, Y, Kuo, Y, \& Huang, C. (2006). Fractionation and identification of 9c, 11t, 13tconjugated linolenic acid as an activator of PPAR $\alpha$ in bitter gourd (Momordica charantia L.). J Biomed Sci, 13(6), 763772. doi: 10.1007/s11373-006-9109-3

23. Del Guerra, S., Marselli, L, Lupi, R., Boggi, U., Mosca, F., Benzi, L., Del Prato, S., Marchetti, P. (2005). Effects of prolonged in vitro exposure to sulphonylureas on the function and survival of human islets. J Diabetes Complicat, 19(1), 60-64.

24. Dlamini, BP. (2006). African indigenous methods of health promotion and HIV/AIDS prevention. (PhD), University of Zulululand.

25. Fowler, MJ. (2008). Microvascular and macrovascular complications of diabetes. Clin Diabetes, $26(2), 77-82$.

26. Gao, H., Huang, Y, Gao, B, Li, P, Inagaki, C, \& Kawabata, J. (2008). Inhibitory effect on $\alpha$-glucosidase by Adhatoda vasica Nees. Food Chem, 108(3), 965-972.

27. Gupta, A., Gupta, R, \& Lal, B. (2001). Effect of Trigonella foenum-graecum (Fenugreek) Seeds on Glycaemic Control and Insulin Resistance in Type 2 Diabetes. J Assoc Physic Ind, 49, 1057-1061.

28. Hafizur, RM., Kabir, N, \& Chishti, S. (2011). Modulation of pancreatic $\beta$-cells in neonatally streptozotocin-induced type 2 diabetic rats by the ethanolic extract of Momordica charantia fruit pulp. Natur Prod Res, 25(4), 353-367.

29. Hesse, G., \& Taubmann, G (1929). Die Wirkung des Biguanids und seiner Derivate auf den Zuckerstoffwechsel. Arch Exp Path Pharmacol, 142 290-308.

30. International Diabetes Federation, IDF. (2015). International Diabetes Federation, Brussels, 2015.

31. Inzucchi, SE., Bergenstal, RM, Buse, JB, Diamant, M, Ferrannini, E, Nauck, M, Peters, AL, Tsapas, A, Wender, R, Matthews, DR. (2012). Management of hyperglycemia in type 2 diabetes: a patient-centered approach position statement of the American Diabetes Association (ADA) and the European Association for the Study of Diabetes (EASD). Diabetes Car, 35(6), 1364-1379.

32. Kaleem, M., Asif, M, Ahmed, QU, \& Bano, B. (2006). Antidiabetic and antioxidant activity of Annona squamosa extract in streptozotocin-induced diabetic rats. Sing Med J, 47(8), 670-675.

33. Kanter, M., Akpolat, M, \& Aktas, C. (2009). Protective effects of the volatile oil of Nigella sativa seeds on $\beta$-cell damage in streptozotocin-induced diabetic rats: a light and electron microscopic study. J Molec Hist, 40(5-6), 379-385.

34. Kim, Y., Jeong, Y, Wang, M, Lee, W, \& Rhee, H. (2005). Inhibitory effect of pine extract on $\alpha$-glucosidase activity and postprandial hyperglycemia. Nutrition, 21(6), 756-761.

35. Kobayashi, Y., Suzuki, M, Satsu, H, Arai, S, Hara, Y, Suzuki, K, Miyamoto, Y, Shimizu, M. (2000). Green tea polyphenols inhibit the sodium-dependent glucose transporter of intestinal epithelial cells by a competitive mechanism. J Agric \& Food Chem, 48(11), 5618-5623.

36. Kong, W., Zhang, H, Song, D, Xue, R, Zhao, W, Wei, J, Wang, Y, Shan, N, Zhou, Z Yang, P. (2009). Berberine reduces insulin resistance through protein kinase $\mathrm{C}$-dependent up-regulation of insulin receptor expression. Metabol, 58(1), 109119.

37. Kubola, J., \& Siriamornpun, S. (2008). Phenolic contents and antioxidant activities of bitter gourd (Momordica charantia L. ) leaf, stem and fruit fraction extracts in vitro. Food Chem, 110(4), 881-890.

38. Kumar, Abbas, AK, \& Jon, A. (2013). Endocrine pancreas Robbins Basic Pathology (9th ed., pp. 739-750): Elsevier Saunders.

39. Kumar, SN., Mani, UV, \& Mani, I. (2010). An open label study on the supplementation of Gymnema sylvestre in type 2 diabetics. J Dietary Supp, 7(3), 273-282.

40. Liu, W., Hei, Z, Nie, H, Tang, F, Huang, H, Li, X, Deng, Y, Chen, S, Guo, F, Huang, W. (2008). Berberine ameliorates renal injury in streptozotocin-induced diabetic rats by suppression of both oxidative stress and aldose reductase. Chinese Med J Beijing-English Ed, 121(8), 706.

41. Lorenzati, B., Zucco, C, Miglietta, S, Lamberti, F, \& Bruno, G. (2010). Oral Hypoglycemic Drugs: Pathophysiological Basis of Their Mechanism of Action. Pharmaceut, 3(9), 3005-3020. 
42. Luo, H., Wang, L, Imoto, T, \& Hiji, Y. (2001). Inhibitory effect and mechanism of acarbose combined with gymnemic acid on maltose absorption in rat intestine. World J Gastroenterol, 7(1), 9-15.

43. Maedler, Kathrin, Carr, Richard D, Bosco, Domenico, Zuellig, Richard A, Berney, Thierry, \& Donath, Marc Y. (2005). Sulfonylurea induced $\beta$-cell apoptosis in cultured human islets. The J Clin Endocrinol \& Met, 90(1), $501-506$.

44. Malik, SA., Bashir, M, Khan, R, \& Iqbal, M. (2009). Serum sialic acid changes in non-insulin-dependant diabetes mellitus (NIDDM) patients following bitter melon (Momordica charantia) and rosiglitazone (Avandia) treatment. Phytomed, 16(5), 401-405.

45. Mathern, JR., Raatz, SK, Thomas, W, \& Slavin, JL. (2009). Effect of fenugreek fiber on satiety, blood glucose and insulin response and energy intake in obese subjects. Phytother Res, 23(11), 1543-1548.

46. McCune, LM., \& Johns, T. (2002). Antioxidant activity in medicinal plants associated with the symptoms of diabetes mellitus used by the indigenous peoples of the North American boreal forest. J Ethnopharmacol, 82(2), $197-205$.

47. Mehnert, H., \& Seitz, W. (1958). Weitere Ergebnisse der diabetesbehandlung mit blutzuckersenkenden biguan-iden. Munch Med Wschr, 100, 1849-1851.

48. Mellem, J., Baijnath, H, \& Odhav, B. (2015). Antidiabetic potential of Brachylea discolor. Afr J Tradit Complement Altern Med, 12(1), 38-44.

49. Mishkinsky, JS., Goldschmied, A, Joseph, B, Ahronson, Z, \& Sulman, FG. (1974). Hypoglycaemic effect of Trigonella foenum graecum and Lupinus termis (leguminosae) seeds and their major alkaloids in alloxan-diabetic and normal rats. Archiv Inter de Pharmacodynamie et de thér, 210(1), 27-37.

50. Muller, H., \& Rheinwein, H (1927). Pharmacology of galegin Arch Exp Path Pharmacol, 125, 212-228.

51. Nahas, R., \& Moher, M. (2009). Complementary and alternative medicine for the treatment of type 2 diabetes. Canadian Fam Physic, 55(6), 591-596.

52. Nair, Sunil, \& Wilding, John PH. (2010). Sodium glucose cotransporter 2 inhibitors as a new treatment for diabetes mellitus. The J Clin Endocrinol \& Met, 95(1), 34-42.

53. Nsimba, RY., Kikuzaki, H, \& Konishi, Y. (2008). Antioxidant activity of various extracts and fractions of Chenopodium quinoa and Amaranthus spp. seeds. Food Chem, 106(2), 760-766.

54. Oberley, LW. (1988). Free radicals and diabetes. Free Rad Bio \& Med, 5(2), 113-124.

55. Okpako, DT. (1999). Traditional African medicine: theory and pharmacology explored. Trends Pharmacol Sci, 20(12), 482485.

56. Oliveira, ACP., Endringer, DC, Amorim, LAS, das Graças, M, Brandao, L, \& Coelho, MM. (2005). Effect of the extracts and fractions of Baccharis trimera and Syzygium cumini on glycaemia of diabetic and non-diabetic mice. J Ethnopharmacol, 102(3), 465-469.

57. Omonzejele, PF. (2008). African concepts of health, disease, and treatment: an ethical inquiry. The J Sci \& Healing, 4(2), $120-126$

58. Ortiz-Andrade, RR., Garcia-Jimenez, S, Castillo-Espana, P, Ramirez-Avila, G, Villalobos-Molina, R, \& Estrada-Soto, S. (2007). $\alpha$-Glucosidase inhibitory activity of the methanolic extract from Tournefortia hartwegiana: an anti-hyperglycemic agent. J Ethnopharmacol, 109(1), 48-53.

59. Park, Y., Boo, H, Park, Y, Cho, D, \& Lee, H. (2007). Antioxidant activity of Momordica charantia L. extracts. Kor J Med Crop Sci, 15(1), 56-61.

60. Peltzer, K, Khoza, LB, Lekhuleni, ME, Madu, SN, Cherian, VI, \& Cherian, L. (2001). Concepts and treatment for diabetes among traditional and faith healers in the northern province, South Africa. Curation, 24(2), 42-47.

61. Persaud, SJ, Al-Majed, H, Raman, A, \& Jones, PM. (1999). Gymnema sylvestre stimulates insulin release in vitro by increased membrane permeability. J Endocrinol, 163(2), 207-212.

62. Rathi, SS., Grover, JK, Vikrant, V, \& Biswas, NR. (2002). Prevention of experimental diabetic cataract by Indian Ayurvedic plant extracts. Phytother Res, 16(8), 774-777.

63. Sabu, MC., \& Kuttan, R. (2002). Anti-diabetic activity of medicinal plants and its relationship with their antioxidant property. J Ethnopharmacol, 81(2), 155-160.

64. Sabu, MC., Smitha, K, \& Kuttan, R. (2002). Anti-diabetic activity of green tea polyphenols and their role in reducing oxidative stress in experimental diabetes. J Ethnopharmacol, 83(1), 109-116.

65. Sarkar, S., Pranava, M., \& Marita, R. (1996). Demonstration of the hypoglycemic action of Momordica charantia in a validated animal model of diabetes. Pharmacol Res, 33(1), 1-4.

66. Schäfer, A., \& Högger, P. (2007). Oligomeric procyanidins of French maritime pine bark extract (Pycnogenol@) effectively inhibit $\alpha$-glucosidase. Diabetes Res \& Clin Prac, 77(1), 41-46.

67. Sen, S., Chakraborty, R, Borah, B, Dey, BK, Sarkar, B, \& Sahariah, BJ. (2014). In vitro anthelmintic and antioxidant potential of fruits of Momordica charantia: A comparative study. Ind J Health Sci, 7(2), 113.

68. Shanmugasundaram, ERB., Rajeswari, G, Baskaran, K, Kumar, BR, Shanmugasundaram, KR, \& Ahmath, BK. (1990). Use of Gymnema sylvestre leaf extract in the control of blood glucose in insulin-dependent diabetes mellitus. J Ethnopharmacol, 30(3), 281-294. 
69. Sharma, RD, Raghuram, TC, \& Rao, N Sudhakar. (1990). Effect of fenugreek seeds on blood glucose and serum lipids in type I diabetes. Eur J Clin Nutr, 44(4), 301-306.

70. Singh, N., \& Gupta, M. (2007a). Effects of ethanolic extract of Syzygium cumini (Linn) seed powder on pancreatic islets of alloxan diabetic rats. Ind J Experim Bio, 45(10), 861-867.

71. Singh, N., \& Gupta, M. (2007b). Regeneration of $\beta$ cells in islets of langerhans of pancreas of alloxan diabetic rats by acetone extract of Momordica charantia (Linn.)(bitter gourd) fruits. Indian J Experim Bio, 45(12), 1055-1062.

72. Slotta, KH., \& Tsesche, R. (1929). Uber biguanide. II. Die blutzuckersenkende Wirkung der Biguanides Ber Dtsch Chem Ges, 62 1398-1405.

73. Soriano-Santos, J, Reyes-Bautista, R, Guerrero-Legarreta, I, Ponce-Alquicira, E, Escalona-Buendía, HB, Almanza-Pérez, JC, Díaz-Godínez, G, Román-Ramos, R. (2015). Dipeptidyl peptidase iv inhibitory activity of protein hydrolyzates from Amaranthus hypochondriacus $L$. Grain and their influence on postprandial glycemia in streptozotocin-induced diabetic mice. Afr J Tradit Complement Altern Med, 12(1) 90-98.

74. Soumyanath, A. (2005). Traditional medicines for modern times: antidiabetic plants. New York: CRC Press.

75. Sterne, J. (1957). Du nouveau dans les antidiabetiques. La NN dimethylamine guanyl guanide (N.N.D.G.). Maroc Med, 36, 1295-1296.

76. Suksomboon, N., Poolsup, N, Boonkaew, S, \& Suthisisang, CC. (2011). Meta-analysis of the effect of herbal supplement on glycemic control in type 2 diabetes. J Ethnopharmacol, 137(3), 1328-1333.

77. Tong, X., Dong, L, Chen, L, \& Zhen, Z. (2012). Treatment of diabetes using traditional Chinese medicine: past, present and future. The Amer J Chinese Med, 40(05), 877-886.

78. Uebanso, T., Arai, H, Taketani, Y, Fukaya, M, Yamamoto, H, Mizuno, A, Uryu, K, Hada, T, Takeda, E. (2007). Extracts of Momordica charantia suppress postprandial hyperglycemia in rats. J Nutr Sci \& Vitaminol, 53(6), 482-488.

79. Ungar, G., Freedman, L, \& Shapiro, SL. (1957). Pharmacological studies of a new oral hypoglycaemic drug. Proc Soc Exp Biol Med, 95(1), 190-192.

80. Virdi, J., Sivakami, S, Shahani, S, Suthar, AC, Banavalikar, MM, \& Biyani, MK. (2003). Antihyperglycemic effects of three extracts from Momordica charantia. J Ethnopharmacol, 88(1), 107-111.

81. Wang, H., Du, Y, \& Song, H. (2010). $\alpha$-Glucosidase and $\alpha$-amylase inhibitory activities of guava leaves. Food Chem, 123(1), 6-13.

82. Wang, Y., Dawid, C, Kottra, G, Daniel, H, \& Hofmann, T. (2014). Gymnemic acids inhibit sodium-dependent glucose transporter 1. J Agric and Food Chem, 62(25), 5925-5931.

83. Wang, Z., Wang, J, \& Chan, P. (2013). Treating Type 2 Diabetes Mellitus with Traditional Chinese and Indian Medicinal Herbs. Evid Based Complement Alternat Med, 2013, 343594.

84. Welihinda, J., Karunanayake, EH, Sheriff, MH, \& Jayasinghe, KS. (1986). Effect of Momordica charantia on the glucose tolerance in maturity onset diabetes. J Ethnopharmacol, 17(3), 277-282.

85. World Health Organisation, WHO. (2012). Traditional and complementary medicine policy. http://apps.who.int/medicinedocs/documents/s19582en/s19582en.pdf

86. Yibchok-anun, S., Adisakwattana, S, Yao, C, Sangvanich, P, Roengsumran, S, \& Hsu, WH. (2006). Slow acting protein extract from fruit pulp of Momordica charantia with insulin secretagogue and insulinomimetic activities. Bio Pharmaceut Bull, 29(6), 1126-1131. doi: 10.1248/bpb.29.1126

87. Yu, R., Hui, H, \& Shlomo, M. (2005). Insulin secretion and action Endocrinology (2nd ed.): Humana Press.

88. Zhou, J., \& Zhou, S. (2010). Berberine regulates peroxisome proliferator-activated receptors and positive transcription elongation factor b expression in diabetic adipocytes. Eur J Pharmacol, 649(1-3), 390-397.

89. Zhou, J., Zhou, S, Tang, J, Zhang, K, Guang, L, Huang, Y, . . Li, D. (2009). Protective effect of berberine on beta cells in streptozotocin-and high-carbohydrate/high-fat diet-induced diabetic rats. Eur J Pharmacol, 606(1), 262-268.

90. Zhou, J., Zhou, S, Zhang, K, Tang, JL, Guang, LX, Ying, Y, . . Li, D. (2008). Chronic effects of berberine on blood, liver glucolipid metabolism and liver PPARs expression in diabetic hyperlipidemic rats. Bio Pharmaceut Bull, 31(6), 1169-1176. 